\title{
Follow-up of infants with cow's milk allergy undergoing early oral immunotherapy
}

Laura Badina $^{1}$, Valentina Carrato $^{2}$, Laura Levantino ${ }^{2}$, Giulia Peruch ${ }^{2}$, Egidio Barbi ${ }^{3}$, Irene Berti $^{1}$, and Giorgio Longo ${ }^{4}$

${ }^{1}$ Institute for Maternal and Child Health IRCCS Burlo Garofolo

${ }^{2}$ University of Trieste Clinical Department of Medical Surgical and Health Sciences

${ }^{3}$ Institute for Maternal and Child Health, IRCCS Burlo Garofolo

${ }^{4}$ Insitute for Maternal and Child Health IRCCS Burlo Garofolo

July 22, 2020

\section{Hosted file}

Letter to the Editor.pdf available at https://authorea.com/users/345306/articles/471556-

follow-up-of-infants-with-cow-s-milk-allergy-undergoing-early-oral-immunotherapy 


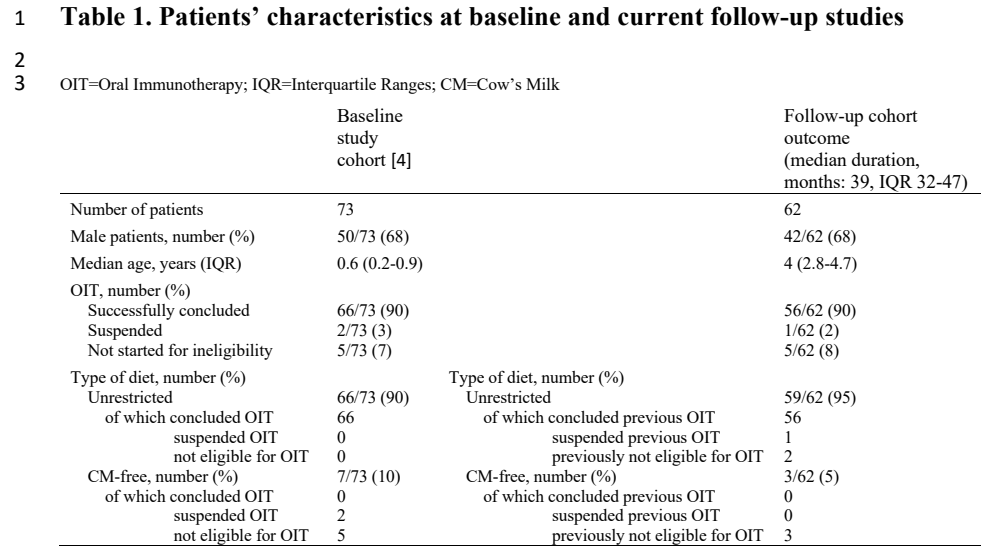

4 